\title{
Impact of Summer Flooding on Viability of Sclerotinia minor and S. sclerotiorum Sclerotia in Soil
}

Michael E. Matheron ${ }^{\dagger}$ and Martin Porchas, University of Arizona, Yuma Agricultural Center, Yuma, 85364

Accepted for publication 21 December 2017.

\section{Abstract}

Lettuce drop, caused by the soilborne fungi Sclerotinia minor and S. sclerotiorum, is an important and destructive disease of lettuce. Research trials in Arizona have shown that some fungicides, such as boscalid and iprodione, can reduce disease incidence up to 50 to $60 \%$. Prior research also demonstrated that viability of S. minor and S. sclerotiorum sclerotia was completely arrested after subjection to a respective 2- and 3-week period of continuous flooding in soil during the summer. Widespread adoption of this cultural disease management tool led to concerns in southwestern Arizona about misuse of a precious resource in an arid environment, damage to drainage canals from excessive ground water, and rising water tables adversely affecting lettuce growth. Overall data from current studies, which compared reduction of sclerotia viability after continuous flooding to less intensive flooding of one 8-h period for 1 to 3 weeks or two 8-h periods for 3 weeks, revealed that continuous flooding was not better than 8-h flooding periods for sclerotia of S. minor but was superior for sclerotia of S. sclerotiorum. Because Arizona lettuce growers have to contend with both species of Sclerotinia, continuous flooding is still the best flooding alternative to achieve virtual elimination of viable sclerotia of both pathogens.
Lettuce drop, caused by the soilborne fungi Sclerotinia minor Jagger and S. sclerotiorum (Lib.) de Bary, is a major disease of lettuce (Lactuca sativa L.), occurring in many lettuce-growing regions of the world (Wu and Subbarao 2017). Infection of leaves and stems contacting soil containing either pathogen leads to development of a brown soft decay. The outer leaves then wilt, followed by collapse of the entire plant, often occurring when lettuce plants are well developed and approaching maturity (Koike et al. 2007). White mycelium and black sclerotia, 3 to 5 and 5 to $10 \mathrm{~mm}$ long for $S$. minor and S. sclerotiorum, respectively, form on decayed crown, leaf, and upper taproot tissue. S. sclerotiorum can also infect upper plant parts not in direct contact with soil by production of aerially dispersed spores. In California (Koike et al. 2007) as well as in Arizona (Matheron and Porchas 2016), losses exceeding 75\% can occur in some severely infested fields. Lettuce has become a major vegetable crop in southwestern Arizona (Yuma County) and southeastern California (Imperial County) from initial seeding in late August through final harvest in early April (Kerns et al. 1999). Fungicides such as boscalid, iprodione, and others are applied to lettuce beds at seeding or after thinning to manage lettuce drop; however, the highest degree of disease reduction attained in efficacy trials, compared with nontreated plants, usually ranges from 50 to $60 \%$ and rarely approaches $70 \%$ (Matheron and Matejka 1989; Matheron and Porchas 2004, 2016, 2017). Greater levels of disease reduction require additional disease management tools. Earlier research demonstrated the effect of temperature and soil moisture on survival of these pathogens. One published report demonstrated that sclerotia of $S$. sclerotiorum completely decayed within 24 to 45 days when subjected to continuous flooding in three

${ }^{\dagger}$ Corresponding author: Michael E. Matheron; E-mail: matheron@ag.arizona.edu

Funding was provided by the Arizona Iceberg Lettuce Research Council.

(c) 2018 The American Phytopathological Society different types of field soils (Moore 1949). Other research revealed that temperatures in the range of 40 to $50^{\circ} \mathrm{C}$ reduced survival of $S$. minor sclerotia (Adams 1975). More recent work showed that no sclerotia of $S$. minor or $S$. sclerotiorum capable of germinating were recovered from soil flooded during the summer in Arizona for a continuous period of 2 or 3 weeks, respectively (Matheron and Porchas 2005). During 2011 and 2012, a total of 2,300 ha of lettuce production land in the Yuma Valley of Arizona was flooded continuously for 3 weeks to virtually eliminate viable sclerotia of both pathogens in soil. Crop production land in southwestern Arizona is mostly laser-leveled to improve irrigation efficiency, which facilitates field flooding (Kerns et al. 1999).

The amount of water needed to accomplish this 3-week summer flooding treatment, depending on soil type, can range from a layer of water 50 to $100 \mathrm{~cm}$ in depth (over 5 to 10 million liters per hectare). For comparison, usually 96 to $127 \mathrm{~cm}$ of water (9.8 to 12.8 million liters per hectare) are required to produce a lettuce crop in southwestern Arizona, although the amount can vary considerably with soil type, temperature, and time of year the crop is grown (Kerns et al. 1999). The volume of water needed to accomplish this 3 -week summer flooding treatment has raised some concerns about this lettuce drop management tool, especially in an arid region that has been in the midst of a drought since 2000 (Udall and Overpeck 2017). Another worry in the Yuma Valley lettuce production region is raising of the water table and related erosion of drainage ditches used for collection of saline ground water from agricultural fields for ultimate transport to the ocean. To address these concerns, the following research was conducted to determine whether flooding soil for less than a 3-week continuous period during the summer could virtually eliminate viable sclerotia of $S$. minor and $S$. sclerotiorum in fields used to grow lettuce.

\section{Production of Sclerotia and Trial Protocol}

Sclerotia of $S$. minor and S. sclerotiorum initially were recovered from naturally infected lettuce plants grown in commercial fields 
in Yuma County, Arizona. Surface sterilization of sclerotia was accomplished by agitation in a $0.5 \%$ solution of $\mathrm{NaClO}$ ( $1: 9$ dilution of household bleach) for $3 \mathrm{~min}$, followed by rinsing in sterile distilled water and then plating on potato dextrose agar (PDA). Mycelium from an actively growing colony arising from a sclerotium of $S$. minor or S. sclerotiorum was placed on fresh PDA plates, and these isolates were used to produce all sclerotia used in field trials. Sclerotia of $S$. minor were produced on potato cubes. Substrate was prepared by placing 15 to 20 cubes of potato tissue (each $1.0 \mathrm{~cm}^{3}$ ) in a series of $125-\mathrm{ml}$ capacity glass flasks, which were autoclaved for $20 \mathrm{~min}$, allowed to cool to room temperature for $24 \mathrm{~h}$, and then autoclaved again. After cooling to room temperature, each flask was inoculated with a mycelial disk from an actively growing culture of $S$. minor on PDA. Following incubation for 4 weeks at $20^{\circ} \mathrm{C}$ in darkness, residual potato tissue was removed from mature sclerotia by washing the contents of each flask in running water within a soil sieve. Sclerotia were air-dried and stored at room temperature $\left(25^{\circ} \mathrm{C}\right)$ in the laboratory until needed. Sclerotia of S. sclerotiorum were produced on barley seed, prepared by boiling $5.5 \mathrm{~kg}$ of this substrate in 15 liters of tap water for $90 \mathrm{~min}$, separating the moist grain from the liquid, and placing $1,000 \mathrm{~cm}^{3}$ of the grain into a series of 2-liter wide-mouth flasks. Flasks were autoclaved for $60 \mathrm{~min}$, allowed to cool to room temperature $\left(25^{\circ} \mathrm{C}\right)$, and then autoclaved again $24 \mathrm{~h}$ later. After flasks had cooled, the grain in each container was inoculated with a mycelial disk from an actively growing culture of $S$. sclerotiorum on PDA. Abundant sclerotia formed after a 6 -week incubation period at $20^{\circ} \mathrm{C}$ in darkness. The contents of each flask were removed, spread out on a clean surface, and air-dried. Sclerotia of S. sclerotiorum were collected from the barley grain substrate and stored at room temperature.

Eight irrigation treatment plots 3-m wide and 18-m long were established at the University of Arizona Yuma Agricultural Center. A $30-\mathrm{cm}$ high soil border was constructed around each plot to confine flood-irrigation water treatments. Each plot was separated by a 3-m buffer strip of land. Nylon-mesh packets, $7.5 \mathrm{~cm}$ long $\times$ $3.8 \mathrm{~cm}$ wide, were each filled with 15 sclerotia of $S$. minor or S. sclerotiorum. Sets of three packets, each containing 15 sclerotia of $S$. minor or $S$. sclerotiorum, were skewered onto wire flags. Five wire flags with packets containing sclerotia of $S$. minor and another five containing sclerotia of $S$. sclerotiorum were placed in each plot, so that packets skewered on each wire were at a soil depth of 0,5 , and $10 \mathrm{~cm}$. Each plot received one of the irrigation treatments listed

TABLE 1
Summer irrigation treatments evaluated in this study
Number

${ }^{\mathrm{z}}$ Each irrigation treatment plot was $3 \mathrm{~m}$ wide, $18 \mathrm{~m}$ in length, and surrounded by a $30-\mathrm{cm}$-high soil border to contain water for flood-irrigation treatments. Each irrigation treatment plot was separated by a $3-\mathrm{m}$ buffer strip of land. in Table 1. When plots were irrigated, a minimum layer of water $3.0 \mathrm{~cm}$ deep was maintained on the soil surface for the duration of each flooding treatment. At the conclusion of the 3-week irrigation treatments, all packets containing sclerotia were recovered from the field once soil in all plots had dried sufficiently. In the laboratory, sclerotia from each packet were thoroughly washed to remove adhering soil, surface sterilized with a 2-min wash with agitation in $70 \%$ ethanol followed by a 2 -min wash with agitation in a $0.5 \%$ solution of $\mathrm{NaClO}$ (1:9 dilution of household bleach), and then after drying plated onto acidified PDA. Acidified PDA, used to suppress bacterial growth, was prepared by adding and thoroughly mixing six drops of an $85 \%$ solution of lactic acid per $250 \mathrm{ml}$ of PDA after autoclaving and cooling to $50^{\circ} \mathrm{C}$ before dispensing into Petri dishes. Viability was determined by the ability of sclerotia to germinate, produce mycelium, and subsequently daughter sclerotia. Sclerotia of $S$. minor and S. sclerotiorum stored in the laboratory at room temperature also were plated onto acidified PDA to compare viability of sclerotia maintained at $25^{\circ} \mathrm{C}$ to those placed in field soil during the summer and either not irrigated or irrigated with water for various periods of time. Specific dates for initiation and termination of each of the three field trials, as well as recorded rainfall, are presented in Table 2. Temperatures recorded at depths of 4 and $8 \mathrm{~cm}$ in soil flooded continuously for 3 weeks and in nonirrigated soil are found in Table 3. Soil moisture (percent volumetric water content) data were collected at the same depths from 3 to 14 days following the 1-week continuous flooding treatment, using a FIELDSCOUT TDR 100 soil moisture meter (Spectrum Technologies, Aurora, IL).

No statistically significant difference was detected between the percentage of sclerotia of $S$. minor or $S$. sclerotiorum that germinated at soil depths of 0,5 , and $10 \mathrm{~cm}$; therefore, data for the three soil depths were pooled prior to analysis. Data from individual

\begin{tabular}{|c|c|c|c|c|}
\hline \multirow[b]{3}{*}{ Year } & \multicolumn{4}{|c|}{$\begin{array}{l}\text { TABLE } 2 \\
\text { neters and recorded rainfall }\end{array}$} \\
\hline & \multicolumn{2}{|c|}{ Duration of trial } & \multirow{2}{*}{$\begin{array}{l}\text { Date sclerotia } \\
\text { removed from } \\
\text { soil }\end{array}$} & \multirow[b]{2}{*}{$\begin{array}{l}\text { Total rainfall }(\mathrm{mm}) \text {, } \\
\text { dates of occurrence }\end{array}$} \\
\hline & $\begin{array}{l}\text { Start } \\
\text { date }\end{array}$ & End date & & \\
\hline 2013 & July 29 & August 19 & August 27 & 27.4 , August 22 to 26 \\
\hline 2014 & July 30 & August 20 & September 12 & 7.9 , August 12 \\
\hline 2015 & July 21 & August 11 & August 27 & 0.0 \\
\hline
\end{tabular}

\begin{tabular}{|c|c|c|c|c|}
\hline \multirow[b]{4}{*}{ Treatment } & maxi & 3 & rature & \\
\hline & \multicolumn{4}{|c|}{ Temperature $\left({ }^{\circ} \mathrm{C}\right)$ at indicated soil depth } \\
\hline & \multicolumn{2}{|c|}{ Minimum } & \multicolumn{2}{|c|}{ Maximum } \\
\hline & $4 \mathrm{~cm}$ & $8 \mathrm{~cm}$ & $4 \mathrm{~cm}$ & $8 \mathrm{~cm}$ \\
\hline \multicolumn{5}{|l|}{2013} \\
\hline Flooded plot & 29 & 30 & 40 & 37 \\
\hline Nonflooded plot & 33 & 34 & 49 & 37 \\
\hline \multicolumn{5}{|l|}{2014} \\
\hline Flooded plot & 24 & 25 & 35 & 34 \\
\hline Nonflooded plot & 29 & 31 & 49 & 44 \\
\hline \multicolumn{5}{|l|}{2015} \\
\hline Flooded plot & 27 & 27 & 35 & 33 \\
\hline Nonflooded plot & 35 & 34 & 54 & 46 \\
\hline
\end{tabular}

${ }^{\mathrm{z}}$ Mean daily minimum and maximum soil temperature recorded at a depth of 4 and $8 \mathrm{~cm}$ from 2 to 7 days after cessation of flooding in the plot flooded continuously for 3 weeks and in the nonflooded plot. 
soil flooding trials as well as the overall sclerotia germination rates for both $S$. minor and $S$. sclerotiorum did not conform to the assumptions of homogeneity of variance or normality; therefore, analysis was performed using the Kruskal-Wallis one-way analysis of variance on ranks nonparametric test, with means compared and separated by the Tukey test $(P=0.05)$. Values for each trial were treated as replicates when analyzing treatment data for overall percentage of sclerotia that germinated for each species of Sclerotinia. The overall effect of each individual treatment on germination of sclerotia of $S$. minor compared with S. sclerotiorum was also assessed. Data points generally did not conform to a normal distribution; therefore, the Mann-Whitney rank sum nonparametric test was used for statistical analysis. SigmaPlot statistical software (Systat Software, San Jose, CA) was used for all statistical analyses.

\section{Effect of Irrigation Duration on Sclerotium Germination}

In two of three trials, there was no difference in final germination of $S$. minor sclerotia among any treatments, including sclerotia that were not subjected to flooding (Table 4). It should be noted, however, that rainfall occurred near the end of these trials (Table 2), which likely affected final viability of sclerotia not receiving a flooding treatment. In contrast, the 2015 trial received no rainfall, and germination of sclerotia of $S$. minor that were not flooded was significantly higher compared with all flooding treatments. Considering overall data for all three trials, germination of $S$. minor sclerotia following continuous flooding for 1 to 3 weeks was significantly lower compared with those not flooded but did not differ from sclerotia subjected to various 8 -h flooding events (Table 4). Sclerotia maintained in the laboratory at $25^{\circ} \mathrm{C}$ germinated at a rate of $94 \%$, a value significantly higher than that observed in overall field trial data.

In two of three trials, germination of $S$. sclerotiorum sclerotia that were not flooded was significantly higher than those flooded continuously from 1 to 3 weeks (Table 4). Significant differences in germination of sclerotia flooded continuously for 1 to 3 weeks compared with those flooded for one or more 8-h periods were not apparent in 2015 but were evident in three and one of the 8-h flooding treatments in 2013 and 2014, respectively. Considering overall data for all three trials, germination of S. sclerotiorum sclerotia following continuous flooding for 1 to 3 weeks was significantly lower compared with those flooded for one or more 8-h periods as well as those not receiving a flooding treatment (Table 4). Sclerotia of $S$. sclerotiorum maintained in the laboratory at $25^{\circ} \mathrm{C}$ germinated at a rate of $87 \%$, a value significantly higher than observed in overall field trial data.

Overall viability of $S$. minor sclerotia after subjection to continuous flooding for 1, 2, and 3 weeks and those not flooded did not significantly differ from values for sclerotia of $S$. sclerotiorum subjected to the same respective treatments $(P=0.920,0.169,0.077$, and 0.721 , respectively). In contrast, the percentage of sclerotia of $S$. minor that germinated after exposure to each of the different 8-h flooding periods was significantly lower than values for sclerotia of $S$. sclerotiorum receiving the same flooding treatment $(P=0.010,0.018$, 0.011 , and 0.017 , respectively). In these trials, conducted in a silty clay loam (7/56/37 sand/silt/clay), sclerotia viability of $S$. minor was more sensitive to intermittent 8-h soil flooding episodes compared with $S$. sclerotiorum. Following the 1-week continuous flooding treatment, the percent volumetric water content of soil at a depth of $4 \mathrm{~cm}$ declined from $64 \%$ at 3 days after cessation of flooding to 44 and $19 \%$ at 7 and 14 days after flooding, respectively. At the $8 \mathrm{~cm}$ soil depth, percent volumetric water content was 92,80 , and $50 \%$ at 3, 7, and 14 days after termination of flooding. Differences in soil water retention at 4 and $8 \mathrm{~cm}$ had no significant impact on the viability of sclerotia of $S$. minor and S. sclerotiorum placed at these respective soil depths.

\section{Disease Management Considerations and Conclusions}

The effect of continuous flooding for 1 to 3 weeks on the capability of sclerotia of $S$. minor and $S$. sclerotiorum to germinate in the current study is similar to findings published earlier (Matheron and Porchas 2005). A major lettuce grower in the Yuma, Arizona, area adopted an 18- to 22-day period of continuous flooding during the summer to rid fields of viable sclerotia of $S$. minor and $S$. sclerotiorum. In most fields treated in this manner, lettuce drop has not reappeared when planted to lettuce, even up to nine years later. In a couple of instances, the same grower had to pull the water off fields after 8 to 10 days, and the resulting reduction of lettuce drop was inferior to that achieved with the longer flooding treatment.

Compared with continuous flooding, one 8-h flooding treatment for 1 to 3 weeks or two 8-h flooding treatments per week for 3 weeks were equally effective in reducing the number of viable sclerotia of $S$. minor but not as effective in deactivating viable sclerotia of S. sclerotiorum.

\begin{tabular}{|c|c|c|c|c|c|c|c|c|}
\hline \multicolumn{9}{|c|}{$\begin{array}{c}\text { TABLE } 4 \\
\text { Effect of summer flooding treatments on viability of sclerotia of Sclerotinia minor and S. sclerotiorumy }\end{array}$} \\
\hline \multirow[b]{2}{*}{ Treatment } & \multicolumn{8}{|c|}{ Percentage of sclerotia that germinated } \\
\hline & 2013 & 2014 & 2015 & Overall $^{\mathbf{z}}$ & 2013 & 2014 & 2015 & Overall ${ }^{\mathbf{z}}$ \\
\hline Soil flooded continuously for 1 week & $2.0 \mathrm{a}$ & $0 \mathrm{a}$ & $2.0 \mathrm{~b}$ & $1.3 \mathrm{~b}$ & $24.7 \mathrm{~b}$ & $0 \mathrm{~b}$ & $4.0 \mathrm{~b}$ & $9.6 \mathrm{~b}$ \\
\hline Soil flooded continuously for 2 weeks & $0 \mathrm{a}$ & $0 \mathrm{a}$ & $0 \mathrm{~b}$ & $0 \mathrm{~b}$ & $2.7 \mathrm{~b}$ & $0 \mathrm{~b}$ & $1.3 \mathrm{~b}$ & $1.3 \mathrm{~b}$ \\
\hline Soil flooded for $8 \mathrm{~h}$ in first week of trial & $13.3 \mathrm{a}$ & $0 \mathrm{a}$ & $6.7 \mathrm{~b}$ & $6.7 \mathrm{ab}$ & $61.3 \mathrm{ab}$ & $12.7 \mathrm{ab}$ & $10.0 \mathrm{~b}$ & $28.0 \mathrm{a}$ \\
\hline Soil flooded for $8 \mathrm{~h}$ in first and second weeks of trial & $6.7 \mathrm{a}$ & $0 \mathrm{a}$ & $2.0 \mathrm{~b}$ & $2.9 \mathrm{~b}$ & $77.3 \mathrm{a}$ & $14.7 \mathrm{ab}$ & $12.0 \mathrm{~b}$ & $34.7 \mathrm{a}$ \\
\hline $\begin{array}{l}\text { Soil flooded for } 8 \mathrm{~h} \text { in first, second, and third weeks of } \\
\text { trial }\end{array}$ & $1.3 \mathrm{a}$ & $2.0 \mathrm{a}$ & $7.3 \mathrm{~b}$ & $3.5 \mathrm{~b}$ & $84.0 \mathrm{a}$ & $16.0 \mathrm{ab}$ & $16.0 \mathrm{~b}$ & $38.7 \mathrm{a}$ \\
\hline Soil flooded for $8 \mathrm{~h}$, twice a week, for three weeks & $14.6 \mathrm{a}$ & $0 \mathrm{a}$ & $0 \mathrm{~b}$ & $4.9 \mathrm{ab}$ & $84.0 \mathrm{a}$ & $21.3 \mathrm{a}$ & $11.3 \mathrm{~b}$ & 38.9 a \\
\hline Soil not flooded & $10.0 \mathrm{a}$ & $2.7 \mathrm{a}$ & $80.0 \mathrm{a}$ & 30.9 a & $18.7 \mathrm{~b}$ & $22.0 \mathrm{a}$ & $56.0 \mathrm{a}$ & $32.2 \mathrm{a}$ \\
\hline
\end{tabular}

${ }^{y}$ Each value for 2013, 2014, and 2015 trials is the percentage of 150 sclerotia of $S$. minor or $S$. sclerotiorum subjected to each treatment that germinated when placed on agar medium supporting their growth. Percent germination for sclerotia of $S$. minor and $S$. sclerotiorum maintained in the laboratory at $25^{\circ} \mathrm{C}$ was $94 \%$ and $87 \%$, respectively. Values within a column followed by a different letter are significantly different $(P=0.05)$ according to the Tukey test.

${ }^{\mathrm{z}}$ Overall percentage of sclerotia that germinated is the mean value of the three trials. 
Because $S$. sclerotiorum sclerotia can form ascospores under favorable cool and wet environmental conditions, this pathogen has the potential to infect and destroy entire lettuce fields. The goal of lettuce growers is virtual elimination of viable sclerotia from fields. The difference between a small percentage of viable sclerotia compared with little or no viable sclerotia in a field may not be statistically significant; however, the presence of a few percent viable sclerotia, especially those of $S$. sclerotiorum that can potentially produce massive quantities of ascospores, is biologically significant. Often, lettuce fields in Arizona may contain both $S$. minor and $S$. sclerotiorum; therefore, flooding fields for a sufficient duration of time to achieve virtual eradication of viable sclerotia of both species of Sclerotinia is deemed to be prudent and justified by growers.

A large degree of variability in sclerotia germination values for S. minor and S. sclerotiorum was noted among the three yearly trials. A possible reason to partially account for the variability in germination rates of $S$. minor sclerotia that were not flooded could be the occurrence of rainfall toward the end of the 2013 and 2014 trials. Mean soil temperature differences among individual trials may have affected final sclerotia germination numbers as well.

Considering the combined values for all three field trials, sclerotia viability for both species of Sclerotinia and for all field treatments, including the nonflooded treatment, was significantly lower than that recorded for sclerotia maintained at $25^{\circ} \mathrm{C}$ in the laboratory. Adams (1987) noted that the time required to kill $50 \%$ of sclerotia of $S$. minor at soil temperatures of $35,40,45$, and $50^{\circ} \mathrm{C}$ was $624,38,3$, and $2 \mathrm{~h}$, respectively. In the current study, maximum soil temperatures recorded in some flooded plots and especially in nonflooded plots were high enough to affect the viability of sclerotia of S. minor and perhaps $S$. sclerotiorum as well. Therefore, reduced sclerotia viability recorded in these studies likely resulted from the combined effects of soil moisture and temperature. The possible role of microorganisms in the inactivation of sclerotia was not addressed in the current study; however, Imolehin and Grogan (1980) noted that Trichoderma spp. were the most numerous among other fungi recovered from field sclerotia of $S$. minor that failed to germinate. The role of soil microorganisms in the inactivation and destruction of sclerotia requires more extensive analysis.

The motivation for conducting this research was to determine whether flooding soil for less than a 3-week continuous period of time during the summer could virtually eliminate viable sclerotia of $S$. minor and $S$. sclerotiorum in fields used to grow lettuce. Continuous flooding for 2 weeks also was effective; however, variability in data among the three trials suggests that a 1-week continuous flooding may not provide the virtual elimination of viable sclerotia desired by growers. Finally, one 8-h flooding episode for 1 to 3 weeks or two flooding events twice a week for 3 weeks were not as efficacious as continuous flooding for eliminating sclerotia of S. sclerotiorum. Original concerns about widespread adoption of a 3-week flooding treatment included (i) raising of the water table in some areas, which could negatively impact lettuce growth, (ii) erosion of drainage ditches used to collect saline ground water from agricultural fields, and (iii) potential public perception that extended flooding of fields in the summer is a waste of a precious resource in an arid region currently in the midst of a multiyear drought. These concerns resulted from the initial adoption and extensive use of soil flooding as a management tool for lettuce drop. However, grower experience has shown that the disease has not appeared in lettuce crops up to at least 9 years after a 3-week continuous flooding treatment. The long-lasting effect of a single 3-week flooding event has drastically reduced the need to frequently reapply this treatment, negating the original concerns related to using this disease management tool. Another positive aspect of using summer soil flooding to manage lettuce drop is that fungicide application for management of this disease is no longer needed in these fields, saving the grower's resources and reducing the overall amount of fungicides needed to manage lettuce diseases.

Water used to irrigate crops in southwestern Arizona is supplied by the Colorado River. Salts contained in this irrigation water build up in crop production fields over time. Lettuce is highly sensitive to salinity; therefore, a common preplant cultural practice is to apply a flood irrigation equivalent to a layer of water 10 to $15 \mathrm{~cm}$ in depth in July or August to move accumulated salts in soil below the lettuce crop root zone prior to creating planting beds and sowing seed (Kerns et al. 1999). Therefore, in addition to effectively preventing lettuce drop and eliminating use of fungicides for management of this disease, a 3-week summer flooding aids in moving excess salts below the root zone of lettuce as well.

\section{Literature Cited}

Adams, P. B. 1975. Factors affecting survival of Sclerotinia sclerotiorum in soil. Plant Dis. Rep. 59:599-602.

Adams, P. B. 1987. Effects of soil temperature, moisture, and depth on survival and activity of Sclerotinia minor, Sclerotium cepivorum, and Sporidesmium sclerotivorum. Plant Dis. 71:170-174.

Imolehin, E. D., and Grogan, R. G. 1980. Factors affecting survival of sclerotia, and effects of inoculum density, relative position, and distance of sclerotia from the host on infection of lettuce by Sclerotinia minor. Phytopathology 70: 1162-1167.

Kerns, D. L., Matheron, M. E., Palumbo, J. C., Sanchez, C. A., Still, D. W., Tickes, B. R., Umeda, K., and Wilcox, M. A. 1999. Guidelines for head lettuce production in Arizona. Publ. no. AZ1099, College of Agriculture and Life Sciences, University of Arizona. https://cals.arizona.edu/crops/vegetables/ cropmgt/az1099.html

Koike, S. T., Gladders, P., and Paulus, A. O. 2007. Vegetable Diseases: A Color Handbook. Academic Press, Boston, MA.

Matheron, M. E., and Matejka, J. C. 1989. In vitro and field comparison of six new fungicides with iprodione and vinclozolin for control of leaf drop of lettuce caused by Sclerotinia sclerotiorum. Plant Dis. 73:727-730.

Matheron, M. E., and Porchas, M. 2004. Activity of boscalid, fenhexamid, fluazinam, fludioxonil, and vinclozolin on growth of Sclerotinia minor and S. sclerotiorum and development of lettuce drop. Plant Dis. 88:665-668.

Matheron, M. E., and Porchas, M. 2005. Influence of soil temperature and moisture on eruptive germination and viability of sclerotia of Sclerotinia minor and S. sclerotiorum. Plant Dis. 89:50-54.

Matheron, M. E., and Porchas, M. 2016. Comparison of fungicides for management of Sclerotinia lettuce drop, 2015. Plant Dis. Manage. Rep. 10:V012.

Matheron, M. E., and Porchas, M. 2017. Effectiveness of fungicides for managing Sclerotinia drop of lettuce, 2016. Plant Dis. Manage. Rep. 11: V006.

Moore, W. D. 1949. Flooding as a means of destroying the sclerotia of Sclerotinia sclerotiorum. Phytopathology 39:920-927.

Udall, B., and Overpeck, J. 2017. The twenty-first century Colorado River hot drought and implications for the future. Water Resour. Res. 53:2404-2418.

Wu, B. M., and Subbarao, K. V. 2017. Drop. Pages 35-38 in: Compendium of Lettuce Diseases and Pests, 2nd Ed., K. V. Subbarao, R. M. Davis, R. L. Gilberston, and R. N. Raid, eds. American Phytopathological Society, St. Paul, MN. 